\title{
The definition of acute respiratory illnesses in general practice
}

\author{
R. E. HoPe-SIMPSON \\ General Practitioner, Cirencester
}

\author{
D. L. MilleR* \\ Deputy Director, Epidemiological \\ Research Laboratory, Central Public \\ Health Laboratory
}

\section{The problems of classifying acute respiratory illnesses}

A well-defined clinical classification was essential for this survey if order was to be imposed on the numerous undifferentiated respiratory illnesses encountered in general practice to which a variety of labels are attached. The classification had to be designed so that it would demonstrate the activities of the various respiratory parasites in the different anatomical areas of the respiratory tract, and yet it had to be so simple and memorable that many different observers would record a particular syndrome in the same terms and remember clearly what they had to do throughout the two years. If the diagnostic categories were too wide distinctions between different illnesses would be missed; if they were too detailed natural syndromes would be artificially fragmented. No existing classification suited our requirements. That which was finally agreed (Miller, Table 1, this symposium) was based on the anato-

* Present address: Department of Community Medicine, The Middlesex Hospital Medical School, Central Middlesex Hospital, London NW10 7NS. mical divisions of the respiratory tract in descending order from nose to alveoli on the assumption that trouble at a particular locus elicits a consistent pattern of symptoms and signs. Eight of the diagnostic categories corresponded with the natural divisions of the respiratory tract and the ninth category, influenza, was used for illnesses in which the toxic-systemic features outweighed local features. The record cards included a reminder to doctors of the main clinical criteria for allocating an illness to a particular diagnostic category and these were kept simple and short (Table 1).

In studies of morbidity in general practice it is usual to record only the diagnosis at the time of first consultation. We know of no study that has reportede on the frequency with which the main anatomical emphasis may be expected to change in the course of an illness-how often Thursday's common cold turns into pneumonia by the next Monday. In fact, although lower respiratory tract illnesses, not initially numerous, received considerable accretions from illnesses that began in the upper respiratory tract, such changes did not greatly affect the pro-

TABLE 1. Simplified system of diagnosis

\begin{tabular}{|c|c|c|}
\hline Anatomical site & Diagnosis & Main clinical feature(s) \\
\hline Nose & Common cold & Nasal discharge \\
\hline $\begin{array}{l}\text { Ear } \\
\text { Throat }\end{array}$ & $\begin{array}{l}\text { Otitis media } \\
\text { Pharyngitis (including tonsillitis) }\end{array}$ & $\begin{array}{l}\text { Earache } \\
\text { Sore throat }\end{array}$ \\
\hline $\begin{array}{l}\text { Larynx } \\
\text { Trachea }\end{array}$ & $\begin{array}{l}\text { Laryngitis } \\
\text { Croup } \\
\text { Tracheitis }\end{array}$ & $\begin{array}{l}\text { Hoarseness } \\
\text { Stridor } \\
\text { Dry cough }\end{array}$ \\
\hline $\begin{array}{l}\text { Bronchi } \\
\text { Bronchiole }\end{array}$ & $\begin{array}{l}\text { Bronchitis } \\
\text { Bronchiolitis }\end{array}$ & $\begin{array}{l}\text { Productive cough, rhonchi } \\
\text { Distended chest, costal recession } \\
\text { fine rales }\end{array}$ \\
\hline Lung & Pneumonia & $\begin{array}{l}\text { Consolidation (diminished air } \\
\text { entry, dullness crepitations) }\end{array}$ \\
\hline General & Influenza & $\begin{array}{l}\text { Sudden onset, headache, } \\
\text { body aches }\end{array}$ \\
\hline
\end{tabular}


portional distribution of illnesses between diagnostic categories (Miller, Table 6, this symposium). Nevertheless, it is clear that the stage at which illnesses reach the doctor's attention is an important variable in determining the diagnostic label that is attached to it.

\section{The clinical features of the diagnostic categories}

Our task here is to explore how clearly and consistently the classification described the illnesses encountered. Later papers will show the degree to which the classification shed light on the anatomical preferences of the parasites.

Our analyses tell only part of the story because the set of agreed definitions was a bare aide-mémoire. Although doctors undoubtedly used the main clinical criteria to allocate each illness to its appropriate anatomical category, their decisions were probably supported, albeit unconsciously, by minor characteristics which could not be recorded or quantified. Cough, for example, occurs in many of the listed diagnostic categories, but the patient with 'laryngitis' has a cough that differs in character from that of the patient with 'bronchitis'. Descriptive terms such as 'croupy cough' may not carry the came connotations to different observers. Such qualitative clues, though valuable, cannot be pre- cisely recorded verbally, but they must have contributed much to the doctors' decisions about classification and so to the validity of the results.

In acute respiratory infections the agent is rarely confined to one part of the respiratory tract and it is not surprising to find that symptoms and signs overlap considerably between different clinical categories. However, certain features or patterns of features might be expected to stand out as characteristic. The percentage frequency of the main clinical features recorded in each diagnostic category are set out in Tables 2-9 (these tables include only those features which are present in at least $30 \%$ of patients in one or more of the four age groups for any particular diagnosis: percentages of $50 \%$ or more are bold type and those of less than $10 \%$ have been omitted). Figure 1 shows the salient features of each diagnosis by age group.

\section{Children aged 0-4}

Coryza, cough and fever were present in at least $30 \%$ of patients irrespective of the diagnosis. Coryza was recorded in all cases of common cold, but it was not a clearly distinguishing feature because it was also present in $40 \%$ or more of patients with other diagnoses. Sore throat, with or without exudate, did not feature commonly in any diagnosis

TABLE 2. Clinical features of common cold and sinusitis ( $\%$ present)

\begin{tabular}{|c|c|c|c|c|}
\hline & \multicolumn{3}{|c|}{ Age (years) } & \multirow[b]{2}{*}{45 and over } \\
\hline & $0-4$ & $5-14$ & $15-44$ & \\
\hline No. of cases & 343 & 171 & 305 & 166 \\
\hline $\begin{array}{l}\text { Coryza } \\
\text { Sore throat } \\
\text { With exudate } \\
\text { Without exudate } \\
\text { Cough } \\
\text { Fever } \\
\text { Headache }\end{array}$ & $\begin{array}{r}99 \\
2 \\
67 \\
41 \\
-\end{array}$ & $\left.\begin{array}{l}96 \\
2 \\
40 \\
72 \\
48 \\
28\end{array}\right\} 42$ & $\left.\begin{array}{l}97 \\
45 \\
60 \\
25 \\
38\end{array}\right\} 49$ & $\left.\begin{array}{r}4 \\
32 \\
71 \\
30 \\
33\end{array}\right\} 36$ \\
\hline
\end{tabular}

TABLE 3. Clinical features of primary otitis media ( $\%$ present)

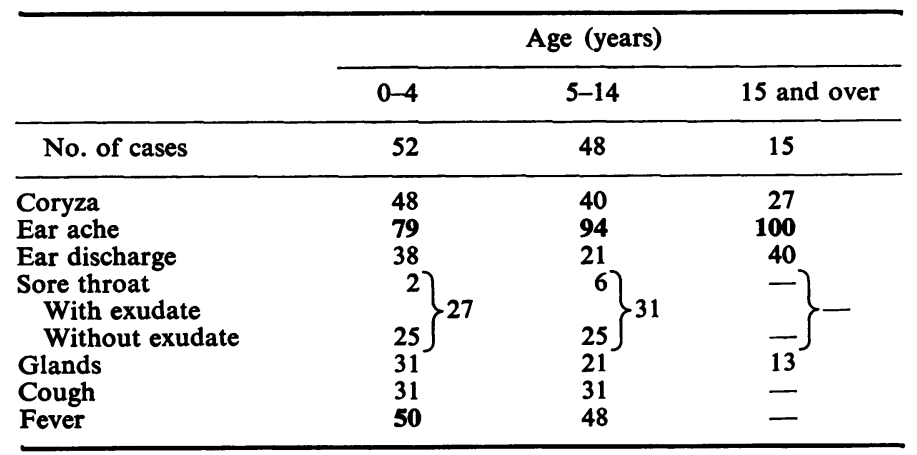




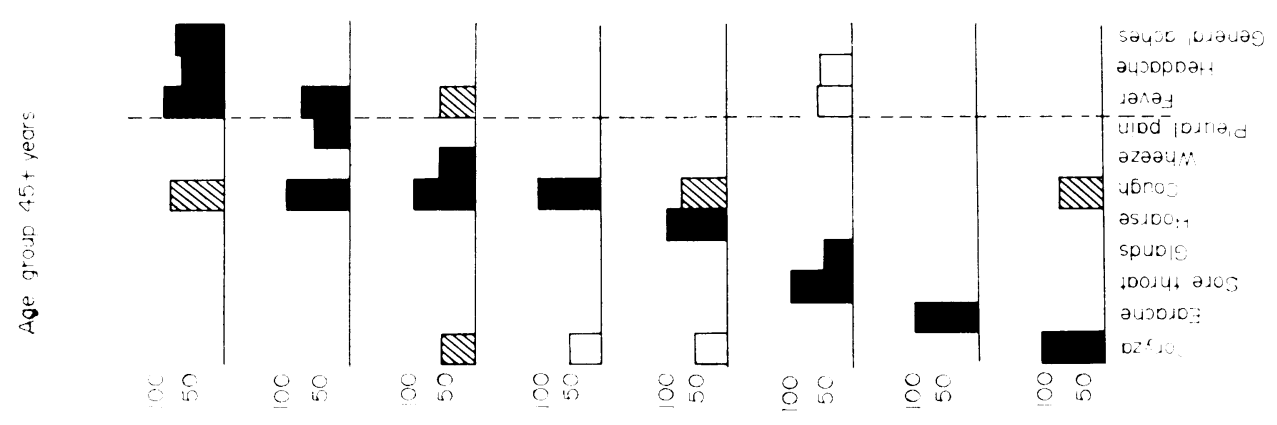

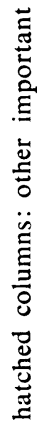
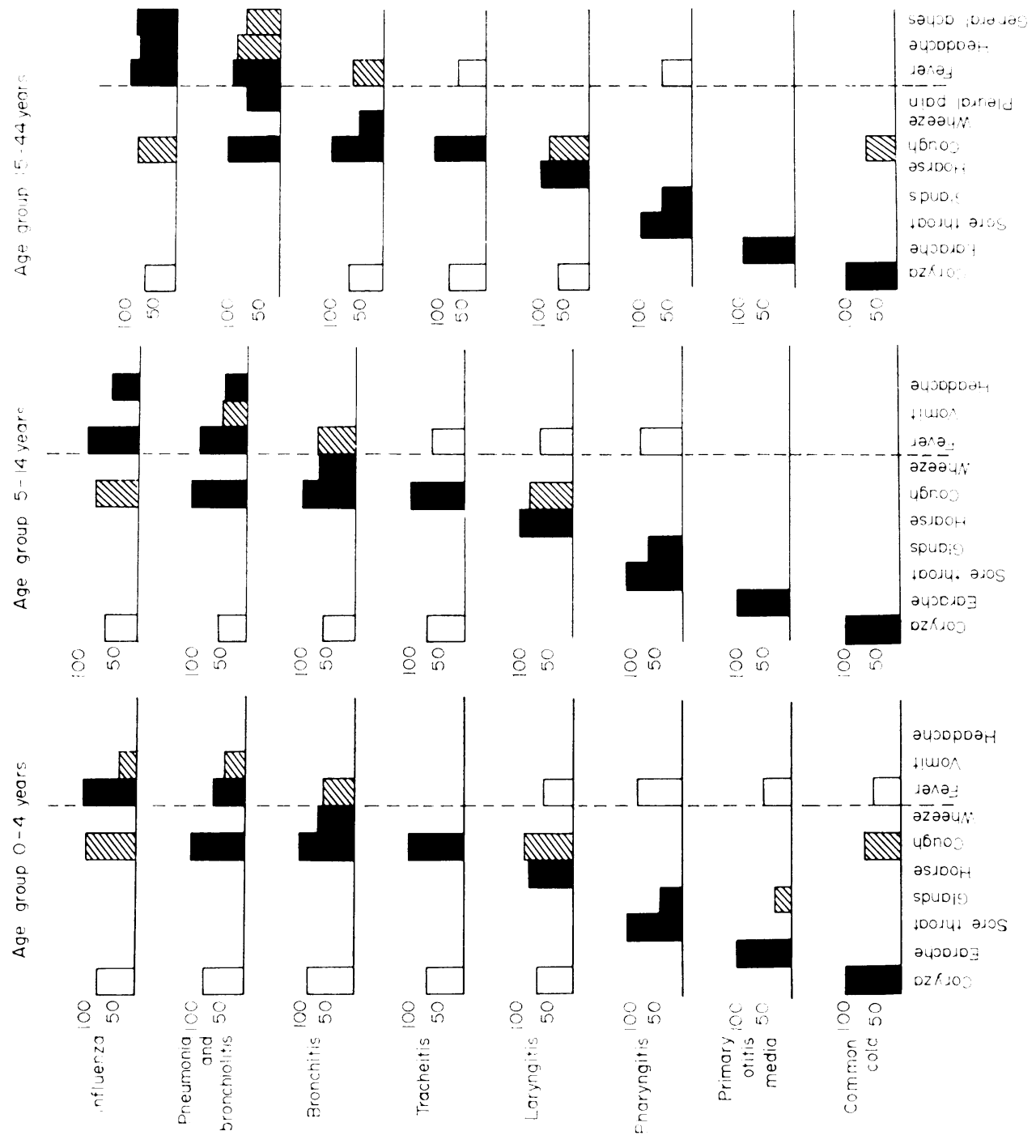
TABLE 4. Clinical features of pharyngitis ( $\%$ present)

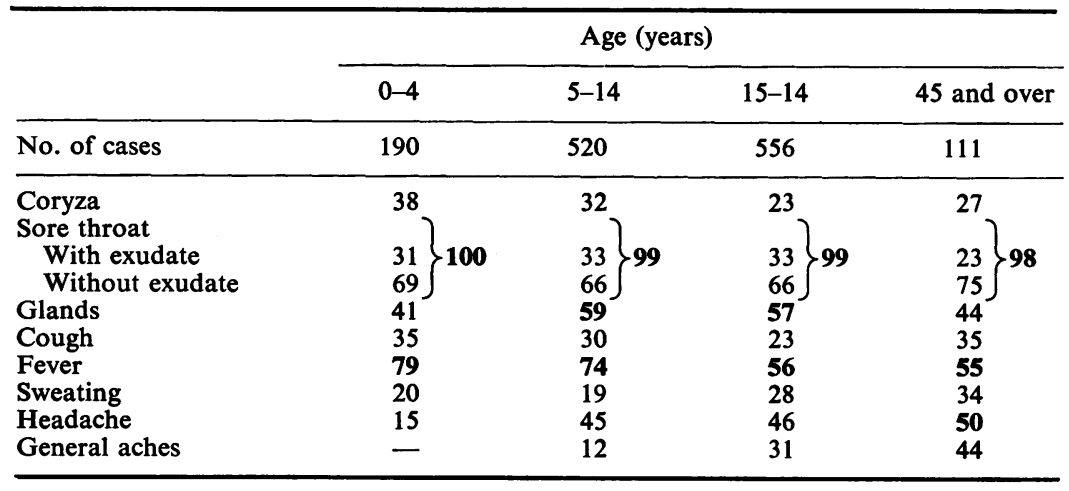

TABLE 5. Clinical features of laryngitis and croup ( $\%$ present)

\begin{tabular}{|c|c|c|c|c|}
\hline & \multicolumn{3}{|c|}{ Age (years) } & \\
\hline & $0-4$ & $5-14$ & $15-44$ & 45 and over \\
\hline No. of cases & 58 & 36 & 58 & 39 \\
\hline $\begin{array}{l}\text { Coryza } \\
\text { Sore throat } \\
\text { With exudate } \\
\text { Without exudate } \\
\text { Hoarseness } \\
\text { Cough } \\
\text { Fever }\end{array}$ & $\left.\begin{array}{r}3 \\
19 \\
81 \\
91 \\
53\end{array}\right\} 22$ & $\left.\begin{array}{l}44 \\
6 \\
44 \\
94 \\
81 \\
53\end{array}\right\} 50$ & $\left.\begin{array}{r}60 \\
3 \\
43 \\
93 \\
74 \\
24\end{array}\right\} 46$ & $\left.\begin{array}{c}51 \\
0 \\
44 \\
95 \\
72 \\
33\end{array}\right\} 44$ \\
\hline
\end{tabular}

TABLE 6. Clinical features of tracheitis (\% present)

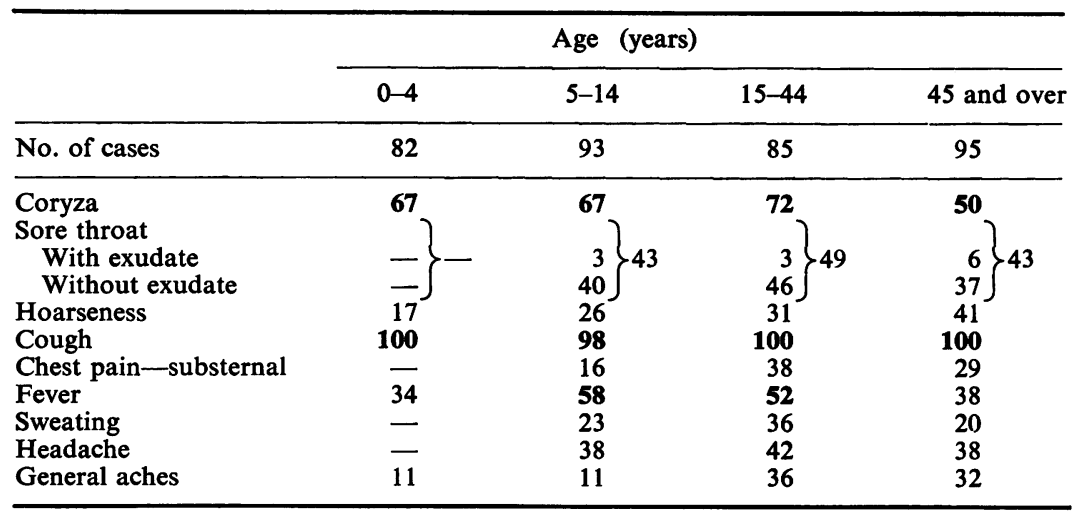

except pharyngitis. Hoarseness showed a similar close and specific correlation with the diagnosis of laryngitis or croup, and earache and/or discharge with otitis media. Enlarged glands were found infrequently in illnesses other than pharyngitis or otitis media. Cough was a less helpful feature since it was present in almost all middle and lower respiratory tract diseases, in two-thirds of the common colds and in one-third of cases of otitis media or pharyngitis. Wheeze was present in two-thirds of the cases of bronchitis, twice as often as in pneumonia or bronchiolitis and featured strongly in no other diagnosis. The proportion of patients with fever varied little between diagnoses $(40-60 \%)$, except for pharyngitis and influenza, in which it was considerably higher. Vomiting was prominent only in pneumonia and influenza. 
TABLE 7. Clinical features of bronchitis ( $\%$ present)

\begin{tabular}{|c|c|c|c|c|}
\hline & \multicolumn{3}{|c|}{ Age (years) } & \\
\hline & $0-4$ & $5-14$ & $15-44$ & 45 and over \\
\hline No. cases & 104 & 58 & 45 & 95 \\
\hline Coryza & 84 & 60 & 64 & 56 \\
\hline $\begin{array}{l}\text { Sore throat } \\
\text { With exudate } \\
\text { Without exudate } \\
\text { Cough } \\
\text { Wheeze } \\
\text { Fever } \\
\text { Sweating } \\
\text { Headache } \\
\text { General aches }\end{array}$ & $\left.\begin{array}{r}2 \\
16\end{array}\right\} 18$ & $\begin{array}{r}3 \\
47 \\
97 \\
67 \\
71 \\
17 \\
28 \\
-\end{array}$ & $\left.\begin{array}{r}4 \\
36\end{array}\right\} 40$ & $\begin{array}{l}2 \\
22 \\
98 \\
58 \\
55 \\
38 \\
28 \\
28\end{array}$ \\
\hline
\end{tabular}

TABLE 8. Clinical features of pneumonia and bronchiolitis ( $\%$ present)

\begin{tabular}{|c|c|c|c|c|c|}
\hline & \multicolumn{4}{|c|}{ Age (years) } & \multirow[b]{2}{*}{45 and over } \\
\hline & $0-4$ & $5-14$ & & $15-44$ & \\
\hline No. cases & 86 & 26 & & 11 & 40 \\
\hline Coryza & 73 & 50 & & 18 & 17 \\
\hline Sore throat & -7 & $0)$ & & 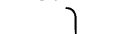 & 2 \\
\hline With exudate & & & 23 & $0\} 36$ & $2\} 17$ \\
\hline Without exudate & - & 23 & & 36 & 15 \\
\hline Cough & 99 & 100 & & 100 & $100^{-}$ \\
\hline Chest pain-substernal & - & 15 & & 27 & 15 \\
\hline Wheeze & 39 & 23 & & - & 30 \\
\hline Chest pain-pleural & 3 & 19 & & 64 & 55 \\
\hline Fever & 56 & 85 & & 91 & 77 \\
\hline Sweating & 8 & 23 & & 45 & 37 \\
\hline Headache & - & 42 & & 82 & 47 \\
\hline General aches & 一 & 15 & & 64 & 45 \\
\hline Prostration & $\overline{25}$ & - & & 36 & 22 \\
\hline Vomiting & 35 & 46 & & 一 & 10 \\
\hline
\end{tabular}

TABLE 9. Clinical features of influenza ( $\%$ present)

\begin{tabular}{|c|c|c|c|c|}
\hline & \multicolumn{3}{|c|}{ Age (years) } & \multirow[b]{2}{*}{45 and over } \\
\hline & $0-4$ & $5-14$ & $15-44$ & \\
\hline No. cases & 70 & 108 & 177 & 123 \\
\hline Coryza & 70 & 59 & 59 & 47 \\
\hline Sore throat & $1)$ & 1) & 27 & $2)$ \\
\hline With exudate & & & & 2 \\
\hline Without exudate & 20 & 48 & $46]$ & 40 \\
\hline Cough & 89 & 78 & 76 & 85 \\
\hline Fever & 96 & 96 & 91 & 93 \\
\hline Sweating & $\overline{-}$ & 20 & 43 & 40 \\
\hline Headache & 20 & 50 & 73 & 68 \\
\hline General aches & 10 & 29 & 77 & 78 \\
\hline Vomiting & 30 & 29 & 17 & 27 \\
\hline
\end{tabular}




\section{Children aged 5-14}

As in younger children, coryza was not a good differentiating feature. Although present in all those with colds it was also present in one-third to twothirds of patients with other diagnoses. Sore throat, with or without exudate, was always present in pharyngitis by definition, but many of those with other diagnoses also had sore throats.

Cough was nearly always present in middle or lower respiratory illnesses, but was by no means confined to these categories. Fever, likewise, was a common feature of most illnesses, but particularly so in pharyngitis, lower respiratory illnesses and influenza. Headache was recorded with moderate frequency $(40-50 \%)$ in several diagnoses. The only really useful distinguishing features were hoarseness in laryngitis, wheeze in bronchitis, earache in otitis media, sore throat and enlarged glands in pharyngitis and vomiting in pneumonia.

\section{Adults}

Coryza was present in all adults with a diagnosis of cold, and sore throat in all those with pharyngitis, but, as in children, these features were by no means exclusive to those diagnoses. In general, up to $70 \%$ of patients with middle and lower respiratory tract illnesses (except pneumonia) had coryza, and up to $50 \%$ of those with diagnoses other than pharyngitis had sore throats. Enlarged glands were recorded in about half of the cases of pharyngitis but not often in other categories of illness. Earache or discharge were common only in otitis media. Hoarseness was almost always present in laryngitis and moderately frequently in tracheitis. Cough was as unhelpful in discriminating between diagnoses in adults as it was in children, being a prominent feature in all patients except those with pharyngitis or otitis media. Wheeze was a feature of bronchitis in adults of all ages and of pneumonia in some older adults. Fever, a less common feature in adults than in children, was nevertheless moderately frequent in most diagnoses. Headaches and general aches were reported most often in influenza, but also featured in pharyngitis, tracheitis and lower respiratory illnesses.

\section{Observer differences in recording frequency of clinical} features related to the same diagnosis

Different doctors recorded the various clinical features with different frequencies in relation to the same diagnosis. This may have been because the illnesses they observed were in fact different, but it may also be because they used different criteria to decide whether any particular feature was present.

It is difficult to know how much weight to give to the frequencies recorded for different clinical features.
How often will exudate develop after the tonsils have been inspected and so escape record? Similar deficiencies must have affected the recording of other clinical features. There is the further problem of degree. How prominent must a symptom be to qualify for inclusion? How much does the threshold for recording differ from one observer to another and from one symptom to another?

Examples of the differences recorded are shown in Fig. 2. In cases diagnosed as common cold in children aged 0-4, all agreed on the presence of coryza, but cough and fever were comparatively rarely recorded in Practice $D$, whereas in four other practices cough was present in about two-thirds of patients and fever in up to half the patients.

In cases of pharyngitis in patients aged 5-14 years, the presence of sore throat with or without exudate was agreed. But the frequency of coryza and glands differed widely between practices. Fever was less variable, but there were also considerable differences in the frequency of features such as cough, headache, sweating and vomiting. In Practice I a number of subsidiary features, including conjunctivitis, rigors, sweating, general aches and prostration were recorded more often than in any other practice.

In cases of common cold in adults aged 15-44, Practice $\mathbf{N}$ recorded little other than coryza and, sometimes, cough. Practice $\mathrm{K}$ recorded a few with sore throats and a larger proportion with cough. The remaining practices all recorded sore throats in about three-quarters of the patients. Practices $L$ and $M$ recorded hoarseness with moderate frequency, and in Practice $M$ conjunctivitis, wheeze, rigors, sweating, headaches and general aches were all recorded more often than elsewhere, although some of these features were also recorded with considerable frequency in Practice $\mathbf{L}$.

There was a very marked contrast between the features of tracheitis recorded in Practices $\mathbf{P}$ and $\mathbf{Q}$. Most features, particularly conjunctivitis, sore throat, hoarseness, substernal chest pain, fever, rigors, sweating, headache and general aches were recorded much more often in Practice $\mathbf{P}$ than in $\mathbf{Q}$.

Influenza, as illustrated by three practices, presented a rather more consistent picture than some other diagnoses, though even in this category variation in the frequency of some features was noticeable.

The effect of this variability between practices is not always easy to assess. When the numbers of patients observed in the majority of practices are reasonably large, exceptional frequencies in one practice do not greatly affect either the averages or the general conclusions. However, when numbers are small a relatively large contribution from one practice may result in a biased picture. 


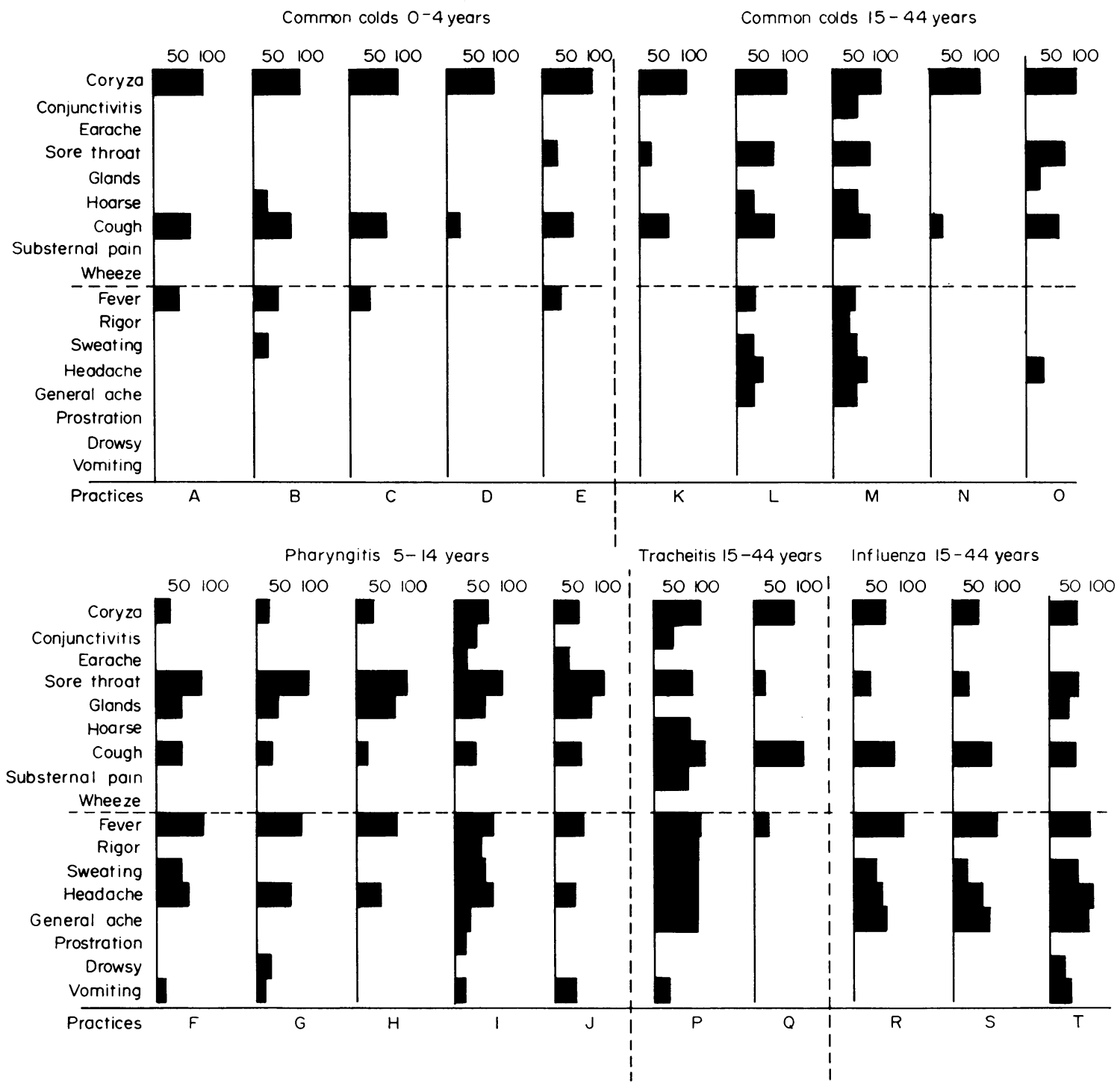

FIG. 2. Frequency ( $\%$ ) of clinical features of the same diagnoses in different practices.

\section{Conclusions}

There is a limited pool of symptoms of respiratory illness, many of which are common to several of the types of illness encountered. Differences between one diagnosis and another, therefore, depend more on the relative severity of different symptoms than solely on their presence or absence. Doctors were guided by the detailed definitions (Miller, Table 1, this symposium) but in practice used a more easily memorable simplification (Table 1) in which diagnostic criteria were reduced to the barest minima.
This method of classification worked by the doctor visualizing the respiratory tract and forming a mental picture of each illness in relation to the portion of the tract that was most acutely affected. When it was difficult to make a decision, for example, if coryza and dry cough were equally troublesome, the ruling was that the lower portion of the tract took precedence. The validity of the classification depended on how accurately the diagnostic criteria indicated trouble in the designated area of the respiratory tract. In the upper tract the assumptions 
were probably correct. Nasal discharge doubtless indicated trouble in the nose, earache trouble in the ear, sore throat an inflamed pharynx, and hoarseness and laryngospasm a disturbed larynx. The significance of dry cough as pathognomonic of tracheal irritation was more open to question. The criteria for pneumonia and influenza were not difficult to apply but were much more difficult to describe succinctly. Some useful but imponderable clues play an important role in the diagnosis of lower tract illnesses.
Despite the difficulty described the classification was reasonably successful in the field and the clinical findings showed concordance with those of the microbiologists and with the more detailed investigations of children in hospital. A simpler classification would not have shown the anatomical preferences of the parasites, whereas more complicated instructions would probably have broken down under the exigencies of general practice.

\section{Discussion}

Questions were asked and discussed in relation to symptomatology. It was queried whether patient's answers to questions read from a record card were truly similar to those spontaneously volunteered and this criticism was agreed. The degree to which the symptoms and signs actually produced a valid separation of the various diagnostic categories was regarded as surprising and it was emphasized that the purpose of the exercise was to seek to pin-point that part of the respiratory tract which was involved in order to seek correlation with the findings of the virologist. 